\title{
Research on the improvement of service quality of new energy vehicles based on User Research
}

\author{
Rong Li \\ Tianjin University of Technology, Tianjin, 300384, China
}

\begin{abstract}
China's new energy vehicle market is still in the initial stage of development, and its development mainly rely on government policy support. But with the continuous improvement of technology and business model, policy support and local protection will gradually fall off, and the improvement of products and services quality is the key point to enhance the inner motivation of new energy vehicles market. So when we continuously upgrade the product quality, the enterprise service quality improvement is also an important link. This paper analyzes the evaluation of existing users and after-sale service of existing users, which based on the questionnaire survey and interviews on the users. Finally, we find the consumers' demand for new energy vehicles' service quality and the problem of new energy automobile service, and then put forward the suggestions for improving the service quality of enterprise.
\end{abstract}

Keywords: New energy vehicle; Service quality; Questionnaire survey; user interview.

\section{基于用户调研的新能源汽车服务品质改善研究}

\author{
李榕 \\ 天津理工大学, 天津市, 中国
}

摘 要: 我国新能源汽车市场尚处于发展初期, 其发展主要依靠政府政策的支持。但随着技术 和商业模式的不断完善, 政策支持和地方保护会逐渐退坡, 新能源汽车产品和服务品质的改 善是提升新能源汽车市场内生动力的要点所在。因此在不断提升产品品质的同时, 企业对服 务环节的品质改善同样是重要环节。本文基于问卷调研和用户访谈, 对新能源汽车现有用户 对汽车购买阶段和售后阶段的服务评价进行分析，找到消费者对新能源汽车服务品质的诉求 以及目前新能源汽车服务环节存在的问题，进而对企业提出服务品质改善提升的建议。

\section{关键词：新能源汽车；服务品质；问卷调研；用户访谈}

\section{1. 引言}

由于能源和环境的双重危机, 新能源汽车被各国视为汽车产业发展的必然趋势, 我国新 能源汽车市场的发展在国家和地方政策的支持下实现产销量的快速增长。在发展公共领域市 场 (出租车、租赁、公交车等) 的同时, 扩展新能源汽车私人消费市场是重中之重[1]。有学 者研究提出, 新能源汽车售后服务体验是影响消费者满意度的重要因素之一 $[2,3]$, 冀鹏辉提 出产品性能、价格、试乘试驾以及服务感受是影响消费者新能源汽车购买决策的主要因素 [4]。 因此, 如何提升新能源汽车的服务品质是新能源汽车市场化发展的重要环节之一。现有研究 中大多集中于新能源汽车产品品质改善的讨论, 有关服务环节的研究还较少。为了弥补现有 研究的不足, 本研究通过问卷调研以及访谈的形式, 对新能源汽车现有用户进行调研, 获取 到用户对新能源汽车服务品质的诉求，最终对企业提出新能源汽车服务改善和市场化推广的 建议。 


\section{2. 基于用户调研的新能源汽车服务品质分析}

本研究收集 325 份新能源汽车用户的调研问卷, 进行了 8 场经销商以及用户的访谈, 现 总结分析如下:

2.1. 购买环节服务品质分析

根据问卷调研和用户访谈，总结新能源汽车购买环节服务特点如下:

2.1.1在重点城市或地区已经建立品牌经销渠道，但经销网络服务能力不强。

虽然新能源汽车的经销商网络有了较大的发展, 但是与传统燃油汽车相比, 新能源汽车 在销售网络及渠道的建设上仍存在以下问题:

(1) 销售终端数量少，销售渠道狭窄

绝大部分汽车生产企业选择通过传统燃油汽车经销商来销售新能源汽车。通过调研, 用 户反映购买新能源汽车时遇到了诸多困扰和不便, 如所在地无新能源汽车经销商, 只能异地 购买; 所在地经销商数量有限，位置偏僻，看车询价十分不便等。

(2) 硬件设施建设不完备

新能源汽车展示不到位、展车和试驾车缺乏使得多数用户并没有试驾过车辆就实施了购 买行为, 可能导致对车辆性能期望过高, 影响用户满意度。另外, 充电基础设施建设不完备 也成为经销网络硬件服务不到位的重要体现。同时, 已经建设的充电设施中还存在故障率高、 缺乏必要的维护以及仅提供经营品牌的充电服务等方面的问题。

（3）销售人员的服务水平和专业性有待提升

新能源汽车是与传统燃油汽车同网络销售, 但是传统燃油汽车经销商对经营新能源汽车 业务准备尚不充分, 销售人员的服务水平和专业知识明显不足，主要体现在：无法提供与传 统燃油汽车同等水平的介绍, 对车辆的性能、使用须知、维修保养等基本信息缺乏了解等。 调研显示仅有 $45.12 \%$ 的用户对销售人员表现出来的专业素质表示满意（图 1）。

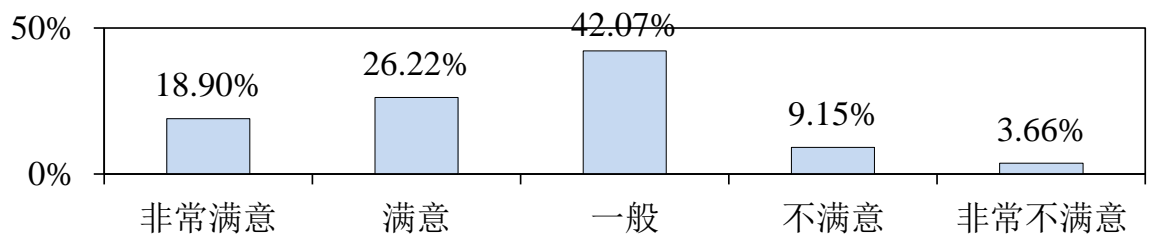

图1 私人用户对销售人员服务的满意度情况

\subsection{2保险便利性有明显改善，但不能满足新能源汽车的特定属性。}

随着新能源汽车保有量的增加, 新能源汽车保险便利性取得了明显改善。但是，与传统 燃油汽车相比, 新能源汽车的保险体系仍不成熟, 尚未建立符合新能源汽车特定属性的保险 体系, 主要问题有投保方案不周全, 赔保存在模糊地带、缺乏电池等核心零部件的专属保险、 投保方式单一等问题。调研显示，有 $61.49 \%$ 的用户对保险便利性表示比较满意或非常满意， 见图 2 所示。

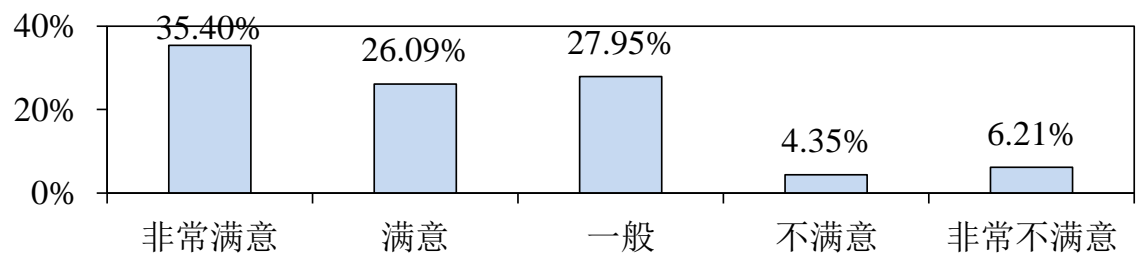

图2 私人用户对新能源汽车购买保险便利性的满意度情况

2. 1.3 贷款购车初步实现, 但贷款便利性有待提升。

从总体上看，目前新能源汽车的贷款购车比例仍然较低，仅有 $10.5 \%$ 的私人用户通过贷 款购买新能源汽车。通过座谈了解到, 很多经销商不提供代办贷款手续服务, 这导致用户陷 入了繁重的贷款申请等事务性工作，且由于对申办手续和流程的不熟悉，增加了用户贷款购 
车的时间成本。同时, 用户对新能源汽车贷款获得利息和手续费的优惠有明显的诉求, 然而 现有的贷款政策无法满足这一诉求，这个问题也直接影响着用户的满意度（图 3）。

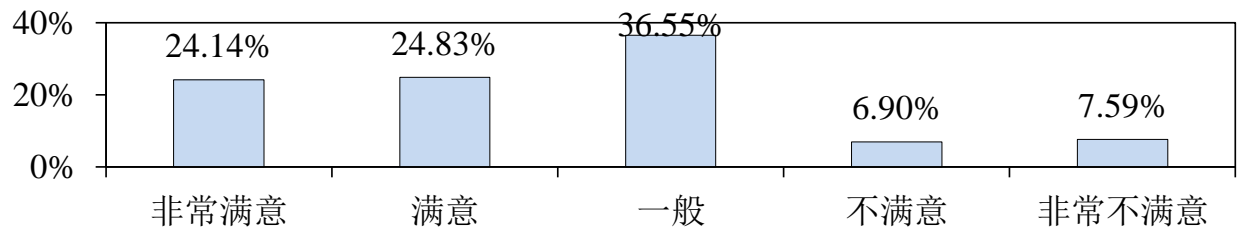

\section{图3 私人用户对新能源汽车贷款便利性的满意度情况}

\section{2. 售后环节服务品质分析}

根据调查，基于新能源汽车私人用户评价的售后环节服务特点如下:

2.2.1公共充电基础设施服务能力无法满足用户需求。

调研结果显示，仅有 $14.49 \%$ 的用户对基础设施的数量表示满意或者非常满意，仅有 17.49\%的用户对基础设施的位置表示满意或者非常满意。用户对于公共基础设施服务能力不 满意的主要原因包括（1）政府机关、公用机构、大型商业区、居民社区等公共区域充换电基 础设施建设进展缓慢, 数量过少, 安装力度不够, 直接制约了用户的充电需求。（2）公共基 础设施的分布不均匀。（3）充电桩接口不统一（图 4）。

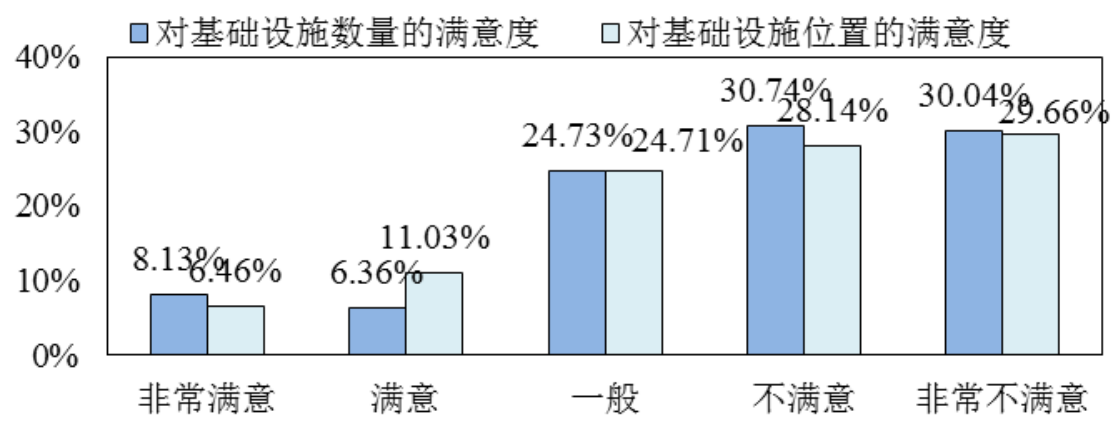

\subsection{2 个人充电桩的安装在具体实施中仍困难重重}

图4 用户对基础设施数量和位置的满意度情况

根据调研数据, 在以家庭充电为主的调研用户中，个人充电桩的安装比例较低。仅有 $31.06 \%$ 的用户安装了个人充电桩, 有 $28.57 \%$ 的用户打算于近期申请安装充电桩; 高达 $40.37 \%$ 的用户近期不打算安装充电桩。大部分没有安装个人充电桩的用户均采用家用电源飞线等方 式来充电，存在一定的安全隐患。

2. 2. 3用户对使用年限期望不高，车型更新置换等售后服务业务比较缺乏。

作为新兴事物，新能源汽车还没有完成一个周期内的使用使命。调研数据显示，用户普 通对车型的使用年限期望不高, 基本与汽车生产企业提供的质保年限相差不大, 维持 5 年左 右的时间。在汽车生产企业质保期结束后能否继续使用和是否有相关的更新置换服务成为很 多用户重点关注的问题。

\section{3. 对企业的建议}

综合以上基于用户的新能源汽车服务品质分析，现给予新能源汽车企业服务品质改善的 建议如下:

（1）购买环节服务品质提升的建议

首先, 提高经销网络的硬件和软件服务能力。

建议进一步加强新能源汽车经销网络建设, 提高覆盖率, 在充分利用好传统汽车销售渠 道的同时, 建立新能源汽车城市展厅等, 为潜在用户提供深度接触新能源汽车的平台。同时, 加强经销商硬件配套设施建设。建议对新能源汽车的销售人员开展专门的培训, 内容包括新 
能源汽车的性能、与竞品的比较、相对的优势等, 并实时跟踪最新的国家政策的动向, 以满 足前来咨询的用户的信息需求。

其次，提升与购买相关的保险、贷款、上牌照等的服务能力。

建议主动开展与各大保险公司的合作, 简化新能源汽车的投保手续, 提供多元化投保方 式，并简化报险环节，提高故障投保的响应速度，提升新能源汽车用户的保险服务满意度。 建议提供更加细致的牌照代办服务, 降低甚至减免代办费。

(2) 售后环节服务品质提升的建议

建议汽车生产企业继续在个人充电桩的安装上给予一定的支持, 在充电桩安装手续的申 领以及实际建设中发挥更大作用，对个人充电设施的安装进行 “全过程组织管理” ，并纳入 到售后服务体系中, 切实将服务落实到用户个人充电设施安装的每一个环节, 显著提高用户 的满意度。

建议不断完善维修保养服务网络建设, 不仅在重点城市增加服务网点, 还要加强培养专 业的新能源汽车维修保养人才。在服务热线上, 建议注重对新能源汽车相关维修保养信息的 更新和核准，充分发挥服务热线的保姆式服务。

建议制定合理的二手车回购、置换、升级等方面的优惠政策，对于电池等核心零部件进 行换购或增容, 在显著提高用户满意度的同时提升用户忠诚度, 进一步提高市场占有率。

\section{4. 结论}

我国新能源汽车市场的发展任重而道远，只有提升市场内生动力方可寻求可持续的发展。 由本研究调研分析可知, 我国新能源汽车企业在服务环节目前存在诸多问题, 用户的满意度 还较低, 因此, 只有在完善新能源汽车产品品质的同时, 努力提升产品购买环节以及售后环 节的服务水平, 才能获得现有用户较高的满意度以及潜在用户的认可, 进而提升新能源汽车 在私人消费领域的销量。

\section{References}

[1] Zhang Tianshu. Inspiration from the development of new energy vehicles in Japan. Renewable energy. Vol. 41 (2014) No. 15, p. 31-36.

[2] Ji Penghui.An empirical study on the factors affecting the attitude of consumers to new energy vehicles (Master's degree, Northeast Normal University, China, 2014).p.31.

[3] Niu Liwei. The influencing factors and guiding policy of new energy vehicle purchase intention. (Master's degree, China University of Mining and Technology, China, 2015).p.24.

[4] Xu Guohu, Xu Fang. A study on the influencing factors of the purchase decision of new energy vehicles. China's population resources and environment. Vol. 57(2010) No. 11, p. 68-72. 